\section{Science for the} citizen

\section{Andrew Clifford}

Strange Weather: Culture, Science, and Technology in the Age of Limits. By Andrew Ross. Verso: 1991. Pp. 275. \$59.95, £32.95 (hbk); \$16.95, £10.95 (pbk). Distributed in North America by Routledge, Chapman and Hall.

SCIENCE informs almost all aspects of everyday life. Its method and metaphors are part of ordinary men and women's conversations about everything from cooking to football to sex. Between professional scientists and the public are discreet and intricate minicultures, such as those of 'new agers', 'cyberpunks' and computer hackers, which locate themselves around the margins of scientific practices and theories; and just as establishment science (as Ross calls it) participates in the ambitions of the political and economic mainstream, so these alternative and often adversarial groupings are to some extent the vanguard of the scientific nonestablishment - that is, the public. Strange Weather is mainly a study of these minicultures, in particular of how they open up and close off science to ordinary people.

Ross's left-libertarian journey begins well with careful studies of individual groups, but too often weighs itself down with apocalyptic and overweening political 'recommendations'. Yet, despite his jaundiced view of the scientific method as being no more valid and every bit as political as any other way of interacting with the world, his perspective does allow him some original insights.

$\mathrm{He}$ begins by scrutinizing the new-age movement, moving on to examine computer hacking, cyberpunk, futurology and global warming. But it is earlier on that he scores most points. In looking at the new-age movement, for example, he points out that although it "dreams us back to the prescientific and to the alchemist's kitchen", it has also assumed "a virtuoso, experimental role in reconstructing a humanistic personality for science": it is, in other words, a rather muddled attempt to restore science in some way to the people. Similarly, Ross examines computer hacking as a form of rebellion. Although unimpressed by 'celebrity' computer hackers, he argues that there are other forms of hacking (which he terms "reconstructive" as opposed to "deconstructive") that convey a lot about their perpetrators' feelings of impotence towards technology (such as the petty sabotage of operating systems by office workers).

Of course, the greater the democra- tization of popular science, the more Ross is pleased, sabotage and theft or not. The strengths and weaknesses of this position are epitomized in the final, largest section on global warming and the new "global weather culture". Ross provides a telling analysis of the Weather Channel on US television, where countries sharing the North American continent appear on the map only "when 'their' weather is seen to be affecting 'ours'... On the weather map, Cuba, for the most part, still does not 'exist'; it does not influence US weather, since the US has no influence over it." He goes on to note that "Instead of feeling the weather as we have felt it historically, as part of a shared local or even national culture, we are encouraged to think of it globally. On the one hand, this will promote our attention to the interdependence of environmental factors across cultures and continents; on the other, it may help to dissipate people's faith in the efficacy of local action."

But if this is true, it's also not true enough. Neither politics nor ecology is

\section{Geological miracles}

\section{Paul G. Davis}

Santana Fossils: An Illustrated Atlas. Edited by J. G. Maisey. T.F.H. Publications: 1991. Pp.459. £125, $\$ 200$.

DEPOSITS characterized by exceptionally preserved fossil faunas, otherwise known as Lagerstätten, are of immense geological importance. The fossil record generally preserves only hard parts of animals and rarely preserves soft tissues, which normally decay without trace. So Lagerstätten give a complete and more accurate picture of diversity within the fossil record (and show just how many animals are not preserved under normal circumstances) as well as yield information about palaeobiology.

The Santana formation in Brazil consists of a variety of strata (from evaporites to lithographic limestones to shales with nodular concretions) housing a host of wonderfully preserved fossils. These Lagerstätten represent a unique 'snapshot' of life during the early Cretaceous period of 145-65 million years ago. Some animals were instantaneously fossilized within the formation (the socalled 'Medusa effect'). Indeed, many of the fish have been so rapidly and perfectly preserved in calcium phosphate that structures such as nuclei of muscle fibres, secondary gill lamellae and stomach wall fragments can still be seen.

The chapters cover basic continental drift, basic cladistics, the sedimentology, an either/or process. It is oversimplifying the situation to argue, as Ross does, that the international call for 'humanity' to be more ecologically responsible conceals and denies the more specific responsibility of large institutions and corporations (although he does not deny the need for large-scale solutions). And far too often his observations metamorphose into guidelines for future political strategies. Worst of all, he really does seem to believe that if power were in the hands of "the people", everything would become ecologically hotsy totsy.

Indeed, so generalized and proletarian does his argument become that he gradually succumbs to the same globalist and omnipotent tendencies as the corporations he believes have done so much harm. Even so, the book contains much food for thought on how science influences everyday life and thus on how all of us cook, play football and have sex.

Andrew Clifford, a freelance writer on cultu$\mathrm{ral}$ trends, is at 25 Keswick House, Crawford Road, London SE5 9NL, UK.

stratigraphy and palaeogeography of the Araripe basin, the placement and relevance of this basin in the opening of the South Atlantic, taphonomy of the fossils (strangely hidden under the title of "Fossil Forensics"), their local collection and preparation, and advanced preparation techniques for the laboratory. The most extensive chapter, which fills most of the book, is a systematic atlas of the fossils.

The formation is renowned for its fossil fish, the most spectacular of which are the three-dimensional specimens that are found in nodules of calcium carbonate. Owing to their aesthetic appeal and large-scale collection by local villagers, these fossil fish can now be found in shops around the world. The descriptions of these fossils fill more than 200 pages of diagnosis, diagrams and colour photographs (it is a pity that some lack scale bars), and are obviously intended for the more serious worker or anyone trying to identify new specimens. The rest of the atlas chapter covers other fossil vertebrates such as pterosaurs (providing a useful English summary of all the German literature on these flying reptiles), frogs, turtles, dinosaurs and crocodiles; the invertebrate fauna, which includes echinoderms, insects, spiders, crustaceans and molluscs; and the fossil plants.

The book brilliantly bridges the gap between semipopular and academic works. In particular, the many highquality colour photographs make it an especially pleasurable read.

Paul G. Davis is in the Department of Geology, University of Bristol, Wills Memorial Building, Queens Road, Bristol BS8 1RJ, UK. 